\title{
DOE/PC/91008--23-Pt, 5 \\ Calculation and \\ Interpretation of Crustal \\ Shortening along the Central \\ Basin Platform, West Texas: \\ A Method to Calculate \\ Basement Motion for \\ Modeling Input
}

T. Hoak ${ }^{a}$, K. Sundberg $b$, and P. Ortolevac

a Kestrel Geoscience, LLC

9683 West Chatfield Avenue, Unit D

Littleton, Colorado 80128

b Phillips Petroleum Company

252 Geoscience Building

Bartlesville, Oklahoma 74003

c Laboratory for Computational Geodynamics

Department of Chemistry

Indiana University

Bloomington, Indiana 47405

MASTER 


\section{DISCLAIMER}

Portions of this document may be illegible in electronic image products. Images are produced from the best available original document. 


\title{
CALCULATION AND INTERPRETATION OF CRUSTAL SHORTENING ALONG THE CENTRAL BASIN PLATFORM, WEST TEXAS: A METHOD TO CALCULATE BASEMENT MOTION FOR MODELING INPUT
}

\author{
T. E. Hoak, SAIC and Kestrel Geoscience, LLC, Littleton CO, \\ K. R. Sundberg, Phillips Petroleum Co., Bartlesville OK, \\ P. Ortoleva, Laboratory for Computational Geodynamics, Indiana University, \\ Bloomington, IN
}

The analysis carried out in the Chemical Interaction of Rocks and Fluids Basin (CIRFB) model describes the chemical and physical evolution of the entire system. One aspect of this is the deformation of the rocks, and its treatment with a rigorous flow and rheological model. This type of analysis depends on knowing the state of the model domain's boundaries as functions of time. In the Andrews and Ector County areas of the Central Basin Platform of West Texas, we calculate this shortening with a simple interpretation of the basin motion and a restoration of the Ellenburger formation. Despite its simplicity, this calculation reveals two distinct periods of shortening/extension, a relatively uniform directionality to all the deformation, and the localization of deformation effects to the immediate vicinities of the major faults in the area. Conclusions are drawn regarding the appropriate expressions of these boundary conditions in the CIRFB model and possible implications for exploration.

To calculate regional shortening, we performed a calculation of the horizontal and vertical components of regional displacement. Under assumptions outlined in the poster, the total strain shortening associated with flexures or folds was calculated. Fault displacement is important and difficult to control. Using an Ellenburger datum composed of several thousand well penetrations, we calculate the incremental $\mathrm{X}, \mathrm{Y}$ and $\mathrm{Z}$ direction shortening on a surface overlying the data grid. From this, we plotted maps showing the magnitude and orientation of the local crustal shortening. Although the grid spacing and data availability strongly influence the calculation, somewhat limiting its applicability, we tested the method along the Central Basin Platform margin. Fault and shortening orientations indicate deformation directions. Given the absence of major thrusts along the eastern margin of this structure, we have been able to calculate the flexure or foldrelated shortening associated with the Ellenburger deformation. We have found a strong correlation between subsurface fault locations and high horizontal shortening gradients. This shortening, when mapped over the general Permian Basin, parallels most major faults and related structural features as reported in the structural geology literature of the area.

\section{DISCLAIMER}

\footnotetext{
This report was prepared as an account of work sponsored by an agency of the United States Government. Neither the United States Government nor any agency thereof, nor any of their empleyees, makes any warranty, express or implied, or assumes any legal liability or responsibility for the accuracy, completeness, or usefulness of any information, apparatus, product, or process disclosed, or represents that its use would not infringe privately owned rights. Reference herein to any specific commercial product, process, or service by trade name, trademark, manufacturer, or otherwise does not necessarily constitute or imply its endorsement, recommendation, or favoring by the United States Government or any agency thereof. The views and opinions of authors expressed herein do not necessarily state or reflect those of the United States Government or any agency thereof.
} 


\section{CALCULATION AND INTERPRETATION OF CRUSTAL SHORTENING ALONG THE CENTRAL BASIN PL.ATFORM, WEST TEXAS: A METHOD TO CALCULATE BASEMENT MOTION FOR MODELING INPUT}

\section{Objectives and Assumptions}

The CIRFB model requires that the basin boundaries be specified as functions of time. The model will predict the stress distributions inside the basin rock volume, and it will model the deformation and fractures in these rocks in response to the stress applied at the basin boundaries and basin floor.

We need to calculate the amount of the basin's deformation that can affect this model. We need to calculate the direction of the deformations, and to the extent possible, their timing.

We assume that

(1) The Ellenburger deformation directly reflects deformation in the basement. That is, the Ellenburger conforms to the basement, so basement deformation will appear as Ellenburger deformation or as cracks in the Ellenburger.

(2) The Ellenburger was essentially flat at the time of deposition. Changes are the result of deformations and rotations of the basement.

(3) These assumptions approximately hold through the deep Paleozoic until the Pennsylvanian unconformity. For purposes of deformation calculation, we will assume the Simpson conforms to the Ellenburger, transmits its deformation, and so on up section.

(4) Deformation of a portion of the formations under the hanging wall block can be neglected and do not affect the sub-thrust sheet out in the basin, away form the bounding faults.

(5) The basic response of the rocks is to deform through fractures. Intense deformation will indicate intense fracturing.

\section{Methods}

Shortening is defined as a difference in length. The only questions are when and where we measure and compare the lengths. Figures $1 \mathrm{~A}$ and IB show a general and close-up view of a deformed surface, $Z(x, y, z)$. We need to calculate the change of length of various lines or sections in the undeformed surface as it is distorted into the deformed surface. In particular, we are interested in the surface changes in the direction of the surfaces' greatest rate of change.

To determine this maximum rate, we need to examine the gradients of the surface. Figures $1 \mathrm{~A}$ and $1 \mathrm{~B}$ will assist this effort. Consider a simple surface embedded in Cartesian coordinates $x, y$ and $z$. The lengths $S, S(x, y)$, and D in Figure $1 B$ are related through Pythagorean theorem. $D$ is the shortening, the difference between $S$ and $S(x, y)$. To find the direction of the greatest of change, we simply calculate the shortening as a function of direction and take the direction of the greatest one. 
If $\alpha$ is the angle between the diagonal $S(x, y)$ and the $x$ axis in Figure $1 B$, we find the maximum change when we solve the eigenvalue problem below for $\alpha$ and $\lambda$.

$$
\begin{aligned}
& \left(\begin{array}{ll}
z_{x}^{2}-\lambda & z_{x} z_{y} \\
z_{x} z_{y} & z_{y}^{2}-\lambda
\end{array}\right)\left(\begin{array}{c}
\cos (\alpha) \\
\sin (\alpha)
\end{array}\right)=0 \\
& \lambda=0 \\
& \lambda=z_{x}^{2}+z_{y}^{2}
\end{aligned}
$$

Of course, the nonzero eigenvalue is the interesting one. With it we obtain both the direction and magnitude of the change in the surface $\mathrm{Z}$. Interestingly, the eigenvalue is just the sum of the squares of the gradients along the axes chosen. The square root of this eigenvalue represents the maximum gradient. It is a calculable and mappable quantity.

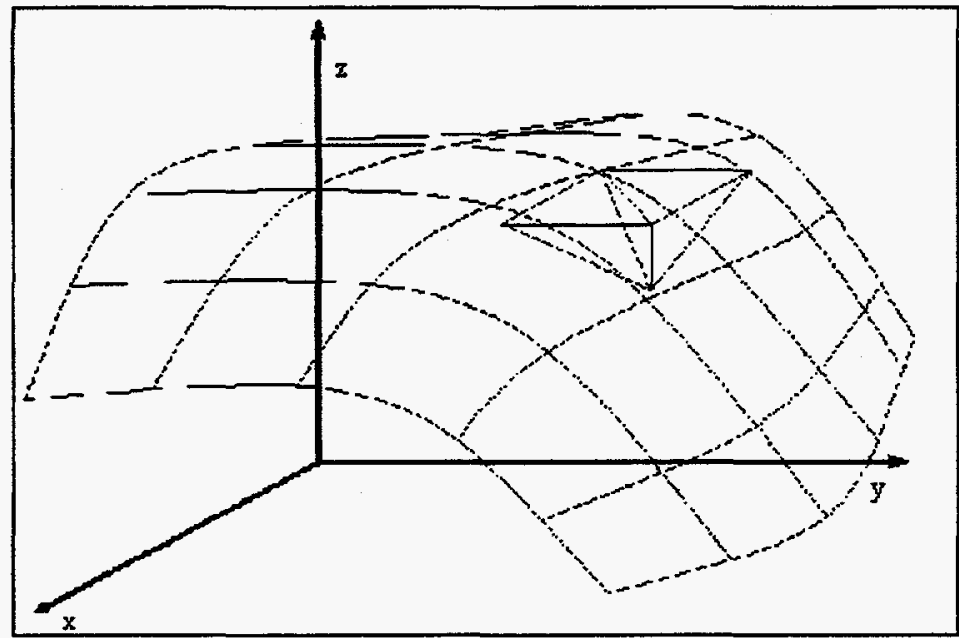

Figure 1A. Coordinate axes $\mathrm{x}, \mathrm{y}$, and $\mathrm{z}$ describe a curved surface. The grid on the surface indicates some differential elements or changes in the coordinate values. The changes in the surface as one moves $\delta x$ and $\delta y$ to produce a change in $\delta z$ are shown in the red figure. This figure is expanded below in Figure $1 \mathrm{~B}$

We are interested in how much the surface was changed as it was distorted from a flat plane into the curved shape seen in Figure $1 \mathrm{~A}$ above.

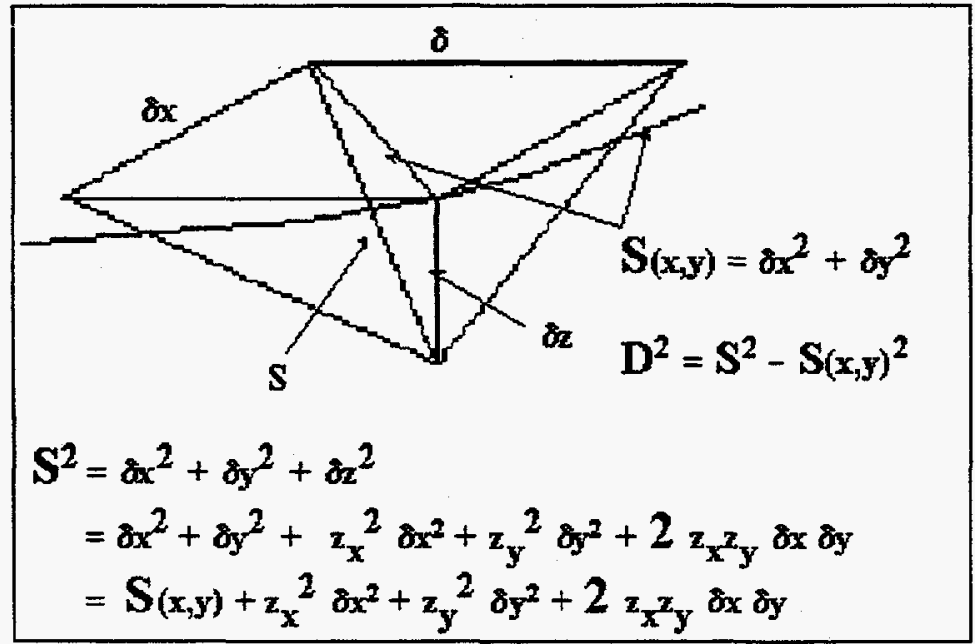

Figure 1B. Basically, the distance $S$, the long diagonal, was stretched from the short red diagonal lying in the plane of $\delta x$ and $\delta y$ and denoted $S(x, y)$ to become $S$. $S$ and $S(x, y)$ have the formulas as shown, and the change in the value of the surface is $D$.

The figures below illustrate the Ellenburger top for the 
general area covering the West Texas and New Mexico Permian Basins. Figure 2 shows the Ellenburger top, and Figure 3 shows the shortening the eigenvalue 1 defines for the areas immediately surrounding Ector County, Texas.
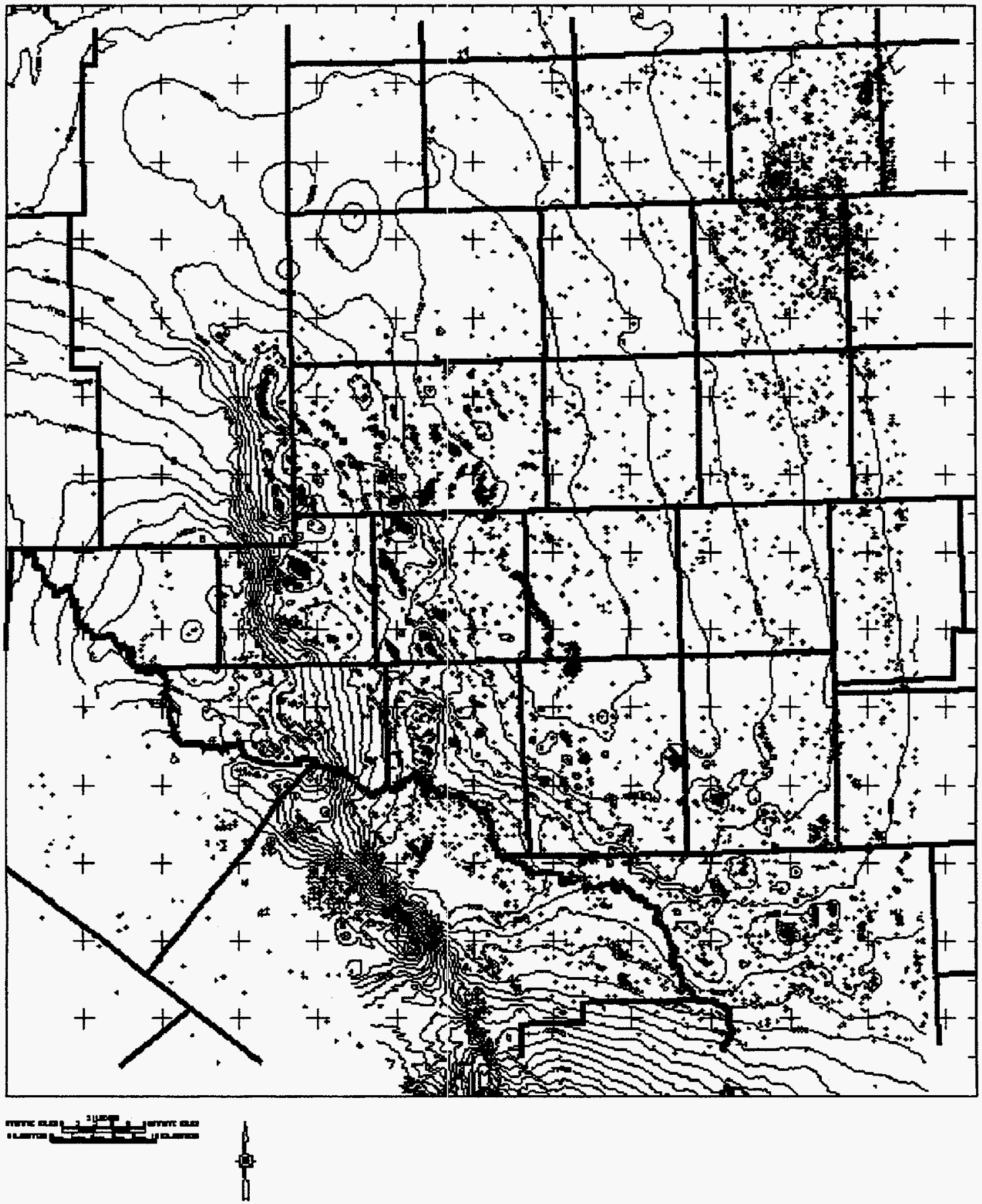

Figure 2. Ellenburger top in the general study area. The map covers the West Texas and New Mexico Permian Basins. Tops are from an edited set of data from the Petroleum Data System. Editing procedures are discussed later 
Now, focusing on the immediate vicinity of Ector County Texas, Figure 3 shows the shortening defined as the eigenvalue of the gradient matrix. The faults are from Gardiner (1990).

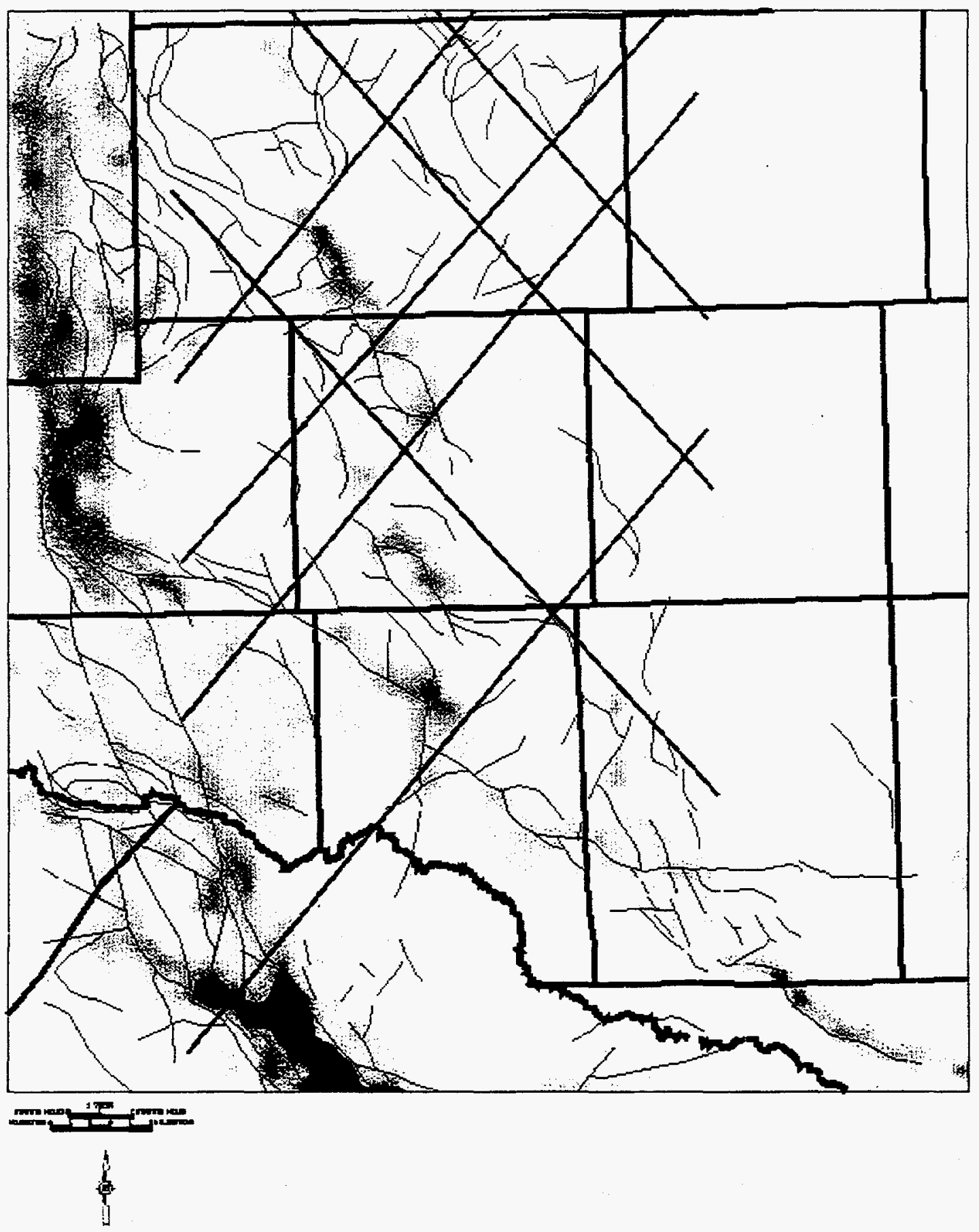

Figure 3. Shortening in the Ellenburger of the Ector County area. The colors are from undeformed, only slightly shortened Ellenburger (light) to strongly deformed Ellenburger (darker). 


\section{Aspects of the Eigenvalue Map}

The strongest deformation clearly coincides with the faults. However, the fault map and the shortening map were, at this point, independently constructed. The following observations are clear,

(1) Primary faults system is NW-SE.

(2) Secondary faults system is NE-SW.

(3) Shortening related distortion is NW-SE; the physical shortening creating the distortion is NE-SW.

(4) The deformation is Quasi-1D. All the motion NE-SW is relatively uniform. There is some strike slip motion along the NE-SW faults, but the shortening eigenvalue map does not indicate much shortening or extension associated with it.

(5) Strain is small.

(6) Distortions are localized near faults.

(7) Deformation is greatest on the down-thrown side of the fault blocks and on their crests.

(8) The shortening features are broad and involve little actual shortening.

\section{Examination of 1D Transect Lines}

The map in Figure 3 shows several transect lines. These are parallel to the direction of shortening that the eigenvalue map indicates is most important. The following figures illustrate a specialization of Figures $1 \mathrm{~A}$ and $1 \mathrm{~B}$ to treat shortening in a $2 \mathrm{D}$ sense along these lines. We begin as in Figures $1 \mathrm{~A}$ and 1B.

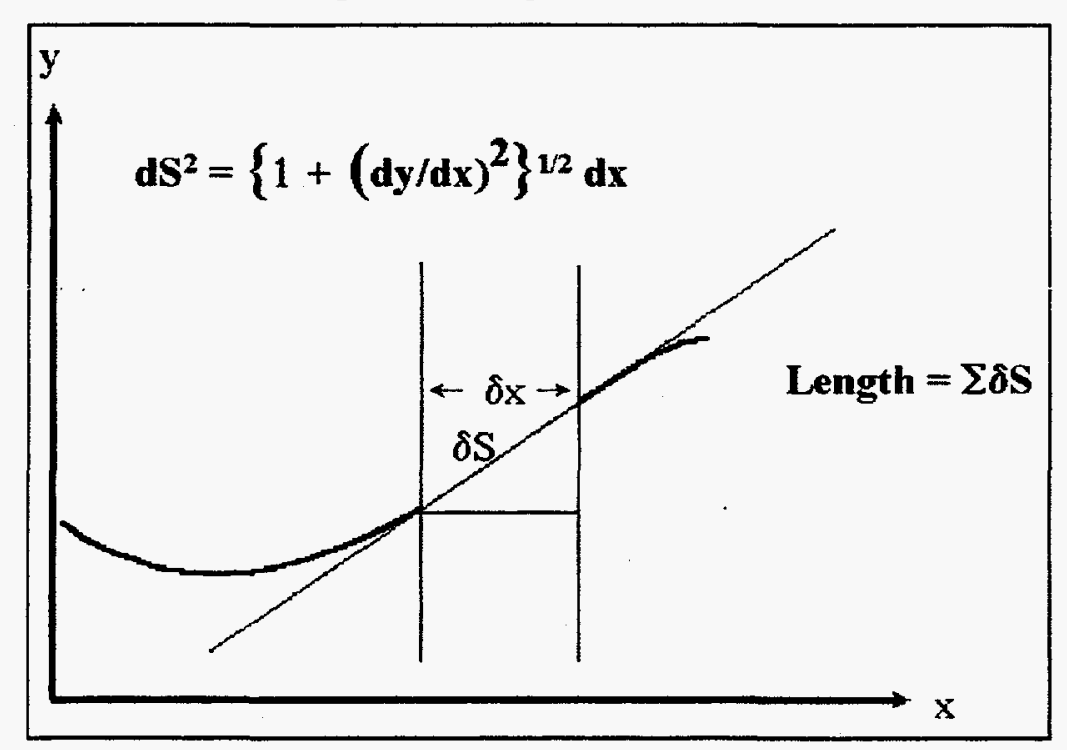

simply be horizontal, then the shortening defined here specialization of the 2D shortening defined earlier.
Figure 4A shows how the distances shown earlier in $3 \mathrm{D}$ are specialized for the linear situation here. The shortening is just the difference between the lengths $\delta S$ and $\delta x$, and $\delta S$ is approximated by the differential form shown. The shortening along a line is just the sum of the individual shortenings at each $\delta x$ interval we define along the length of the line. If we take the reference surface to would be exactly a ID 
However, it is possible in 1 dimension to calculate the shortening of two surfaces relative to each other. The times of depositions of these surfaces then gives us the means to calculate the shortening as a function of time.

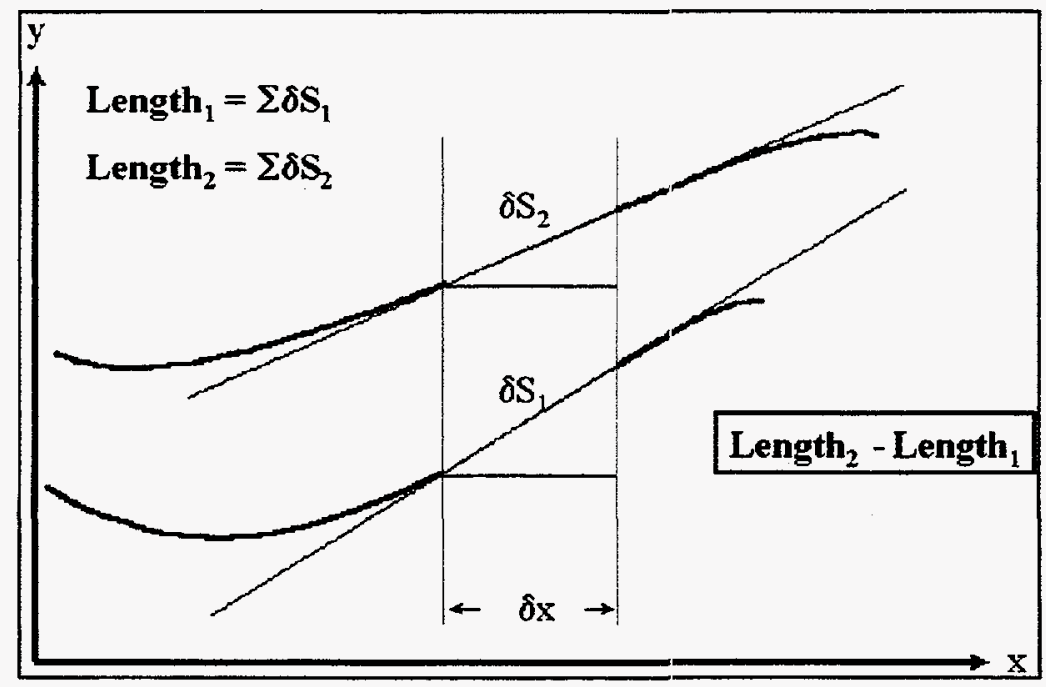

Figure 4B. The lengths of two transects across two surfaces can be defined as easily as one length. If all the formations conform downward, as the Ellenburger and the basement, the difference between these lengths is the shortening that occurred in the lower formation during the time the rocks between these surfaces were deposited

Assuming relatively uniform deposition, which we do in the Paleozoic of this area, the difference in length, Length ${ }_{2}$ - Length ${ }_{1}$, is the amount formation 1 was shortened while formation 2 was being deposited. Formation 2 is thicker in some areas than in others. We are assuming formation 2 is flat where it is deposited, and the changes in thickness are responses to changes in the length (shortening or extension) of formation 1 beneath it.

\section{Compensation for Faulting}

Of course, this argument can be repeated up the section. If we do so, a set of shortening curves is produced and displayed on transect lines. In these transects, a direct application of the shortening calculated above would treat shortening as a drape over faults in the basement. In this case, the shortening would be exaggerated, and we need to find a way to explicitly allow for the faulting in the movement calculations. This is done with a threshold test applied as follows:

(1) The NE-SW (dip line) sections shown in Figure 3 are divided into discrete intervals. In our case, we chose intervals of $325 \mathrm{~m}$.

(2) The shortening is calculated at each interval, moving from NE (in the stable area of the Midland Basin) toward the SW (the basin bounding fault through Ector County and the deep end of the Delaware Basin). The methods of Figures $4 \mathrm{~A}$ and $4 \mathrm{~B}$ are applied directly.

(3) If the shortening is some threshold fraction of the discretization grid size (in our case, $325 \mathrm{~m}$ ), then we say that a fault has occurred in this grid interval.

(4) We assume the faults to be vertical, and the shortening is calculated along a surface projects through the fault as we see in Figure 5. 
(5) The shortening due to crustal shortening, not vertical fault motion, is then the shortening of our simple geometric analysis from Figures 4A and 4B.

\section{Shortening Across}

Faults

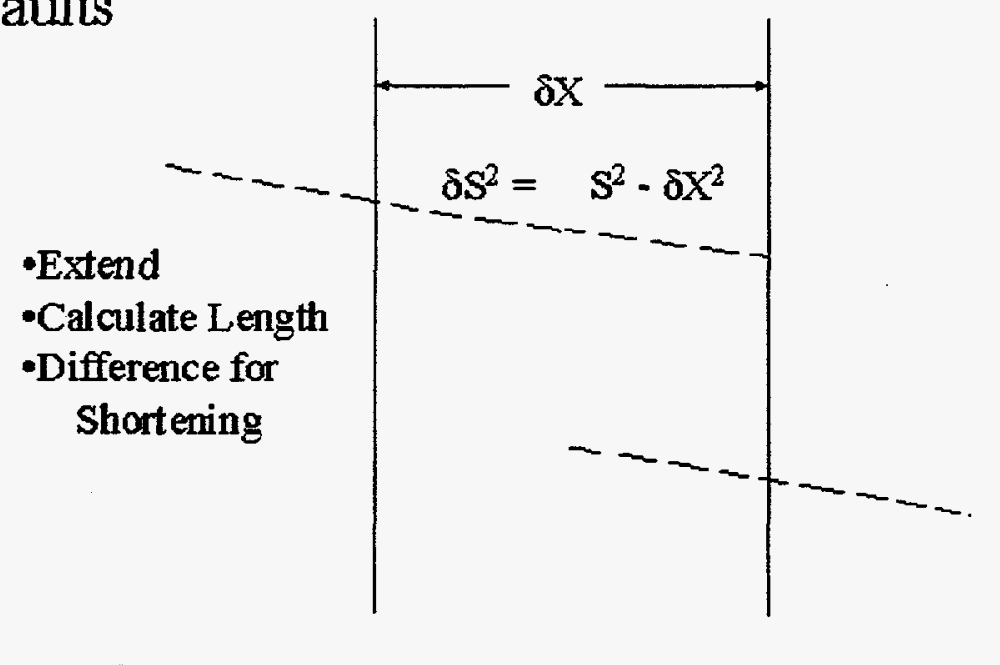

Figure 5. Projection of a surface across a vertical fault defines a shortening that does not count the throw on the fault as part of the shortening. The projection is made in the direction the section is being constructed. In our case, the sections are anchored in the NE, in the center of the Midland Basin. Thus, in this Figure, the NE would be to the left.

Figures $6 \mathrm{~A}$ to $6 \mathrm{E}$ show the fault corrected shortening in the Midland Basin and the Central Basin Platform. In this analysis, all the shortening takes place in the Ellenburger formation. The different lines on the transect plots show the shortening in the Ellenburger at different times. We have chosen

(1) Ellenburger to Barnett

$$
\begin{aligned}
& (\sim 497-320 \text { m.y. }) \\
& (\sim 320-305 \text { m.y. }) \\
& (\sim 305-270 \text { m.y. }) \\
& (\sim 270-261 \text { m.y. }) \\
& (\sim 260-\text { present m.y. })
\end{aligned}
$$

The younger Permian tops are included more to define burial rates than define deformation. These formations are rather uniform in the post Pennsylvanian. Deformation is minor, and deformation that does occur is related to drape over older features. This drape is treated in the analysis of Figures $4 \mathrm{~A}$ and $4 \mathrm{~B}$.

Figure $6 \mathrm{E}$ shows one line (number 4) without the fault corrections above. The drape effects are clearly visible, and the faults are clearly located. The section illustrates the extent to which the data, grid, and contouring in Figure 2 indeed honored the faults.

\section{Conclusions}

Given these plots and the foregoing analysis, we conclude: 
(1) Midland deformation is Quasi-1D. The NE-SW direction predominates. Faults parallel to this trend show little 2D shortening on the map of Figure 3.

(2) Strain is small. Shortening is only a few $100 \mathrm{~m}$ over the width of the basin.

(3) Strain is localized near faults. Large areas of the basin show little distortion in Figure 4. The larger distortions, indicated in the warm colors, are located near the faults.

(4) Deformation is concentrated in the down-thrown blocks and to a lesser extent on the crests of up-thrown blocks. Tectonic stress related fracturing will be concentrated in these areas. The fracturing known to occur in less distorted areas will probably be depositional and karstic in nature.

(5) Early extension and later compression is seen in the sections. The Ellenburger is extended during the Ord to Penn, but it undergoes compression throughout much of the rest of its history. All the effects are small.

(6) Fractures will occur in the distorted areas, and as seen in the close association between the faults and the shortening; these fractures will follow the major tectonic trends of the basin. The brittle lithology of the rocks will let the fractures occur even in the presence of small distortions.

(7) Karst formation is related to near surface water motion. Since the fractures are expressed during deposition, they will to some extent control this water movement. Dissolution will follow the fractures.

\section{BIBLIOGRAPHY}

Gardiner. W. D., 1990: Fault fabric and structural subprovinces of the Central Basin Platform: A model for strike slip movement; Permian Basin Oil and Gas Fields: Innovative Ideas in Exploration and Development, Midland, Texas, West Texas Geologic Society Publication 90-87, 15-27

Hoak, T. E., Sundberg, K. R., Ortoleva, P., and Shebl, M., 1998: Structural synthesis and tectonic interpretation for an integrated modeling study of Ellenburger and Clear Fork Reservoirs, Permian Basin, West Texas, West Texas Geologic Society PROC from AAPG West Texas Section Ann. Sec. Mtng., PROC, 12 pages 

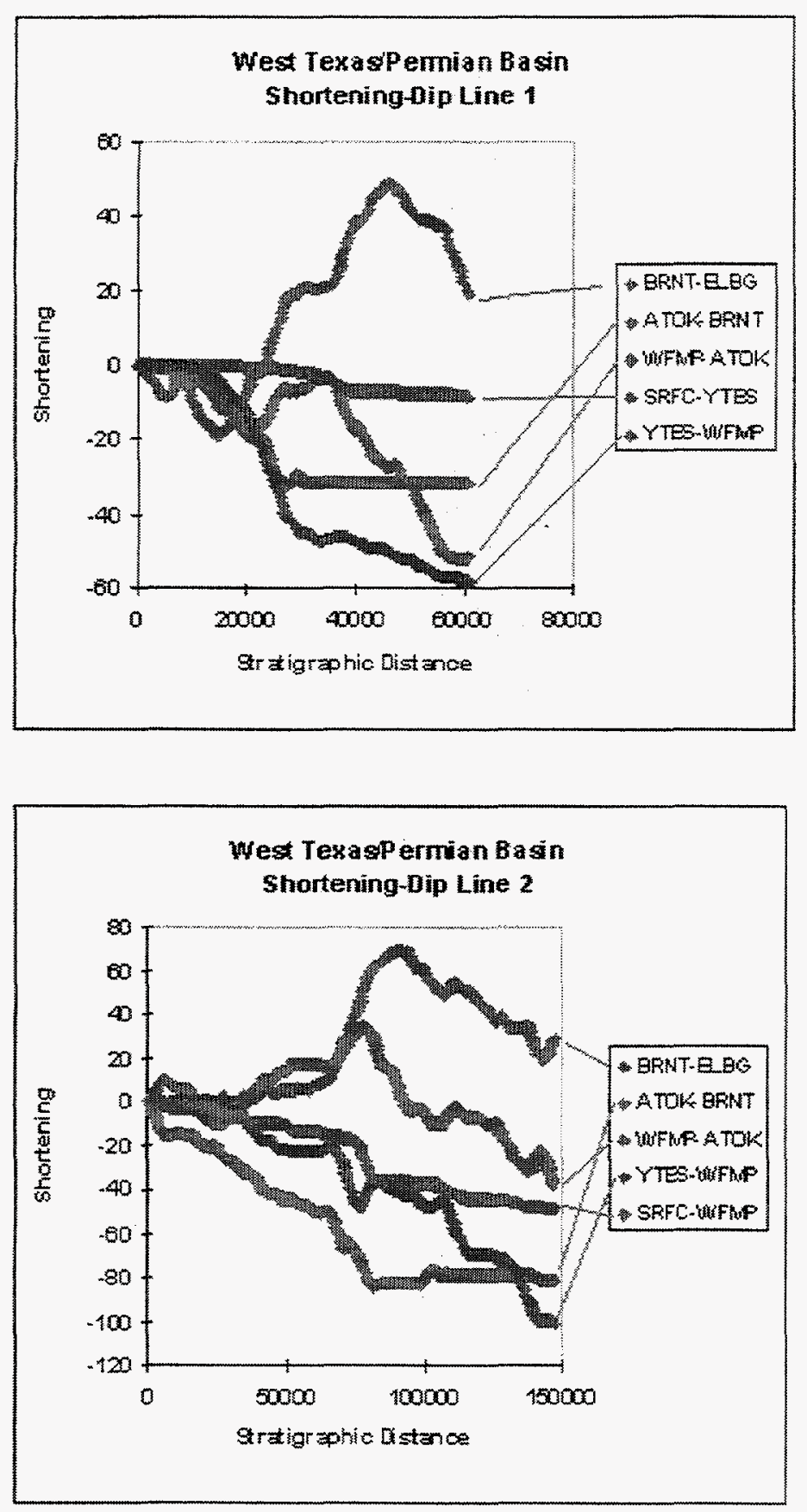

Figure 6A. North most dip line. The Midland Basin in the $E$ is to the left, the Central Basin Platform and Delaware Basin are to the right. This section ends in the Central Basin Platform.

Figure 6B. Dip line just south of Figure 6A. The Midland Basin in the $\mathrm{E}$ is to the left, the Central Basin Platform and Delaware Basin are to the right. This section shows the deep rocks at the east end of the Delaware Basin. 

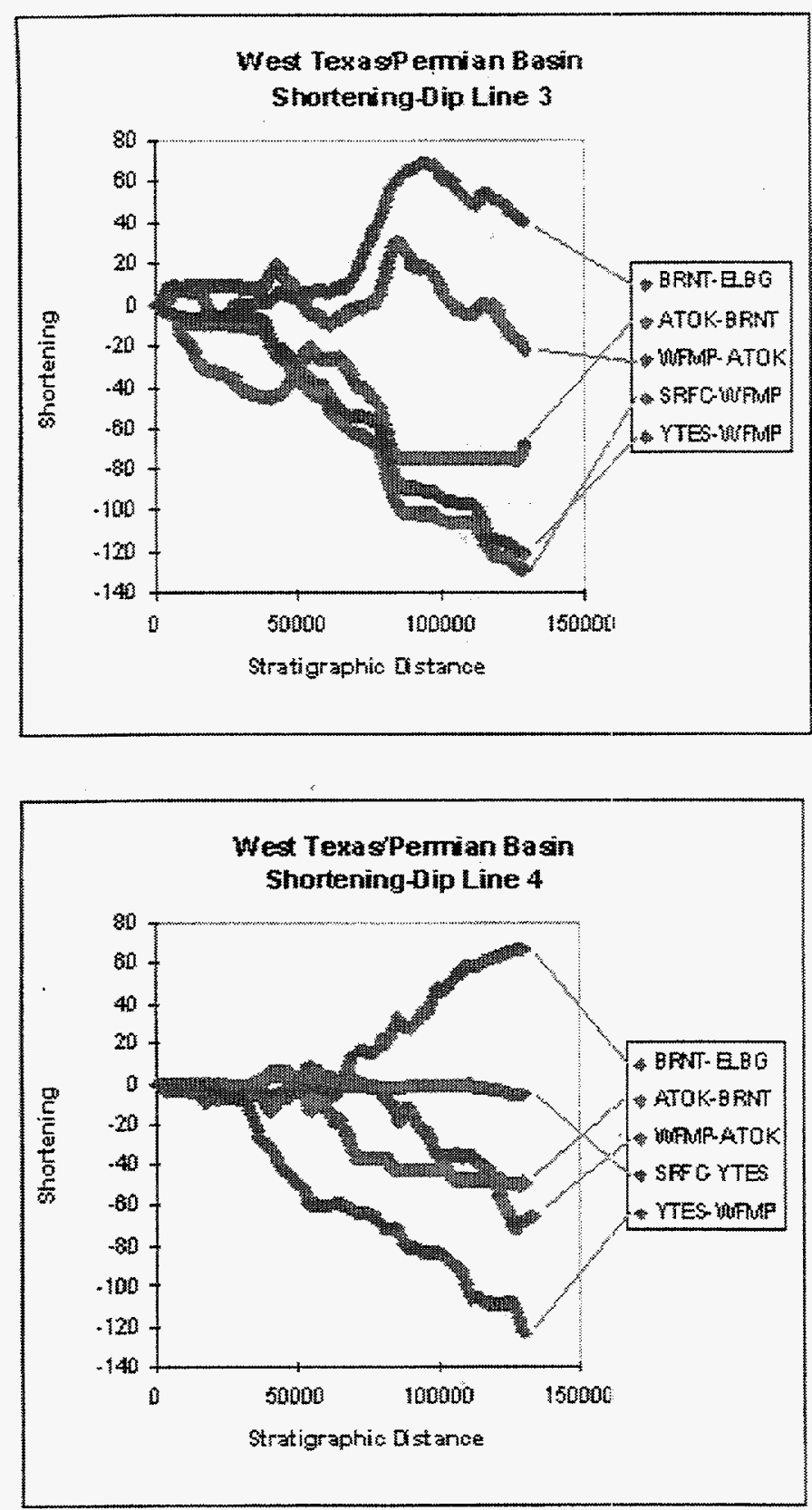

Figure 6C. Dip line just south of Figure 6B. The Midland Basin in the $E$ is to the left, the Central Basin Platform and Delaware Basin are to the right.

Figure 6D. Dip line just south of Figure 6C. The Midland Basin in the $\mathrm{E}$ is to the left, the Central Basin Platform and Delaware Basin are to the right. 


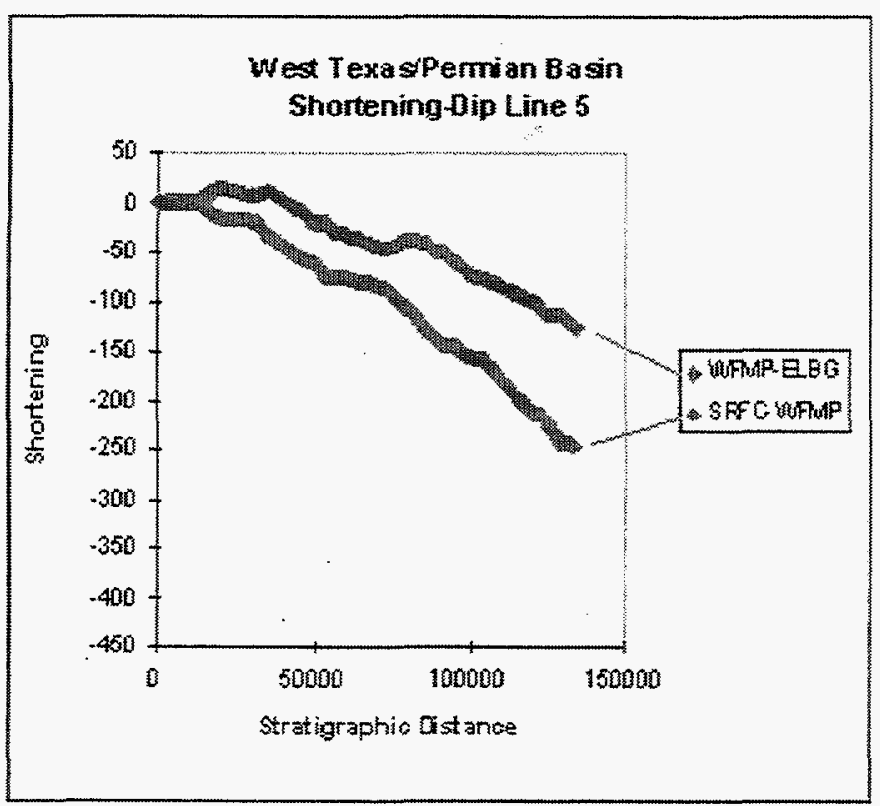

Figure 6E. Dip line just south of Figure 6D. The Midland Basin in the $\mathrm{E}$ is to the left, the Central Basin Platform and Delaware Basin are to the right.

This figure contains a very substantial fault defining the east wall of the Delaware Basin, and erosion has completely removed many formations used above. The only contacts preserved are Ellenburger to Wolfcamp and Wolfcamp to surface.

This area is well south of the project area and need not be described for purposes of this work.

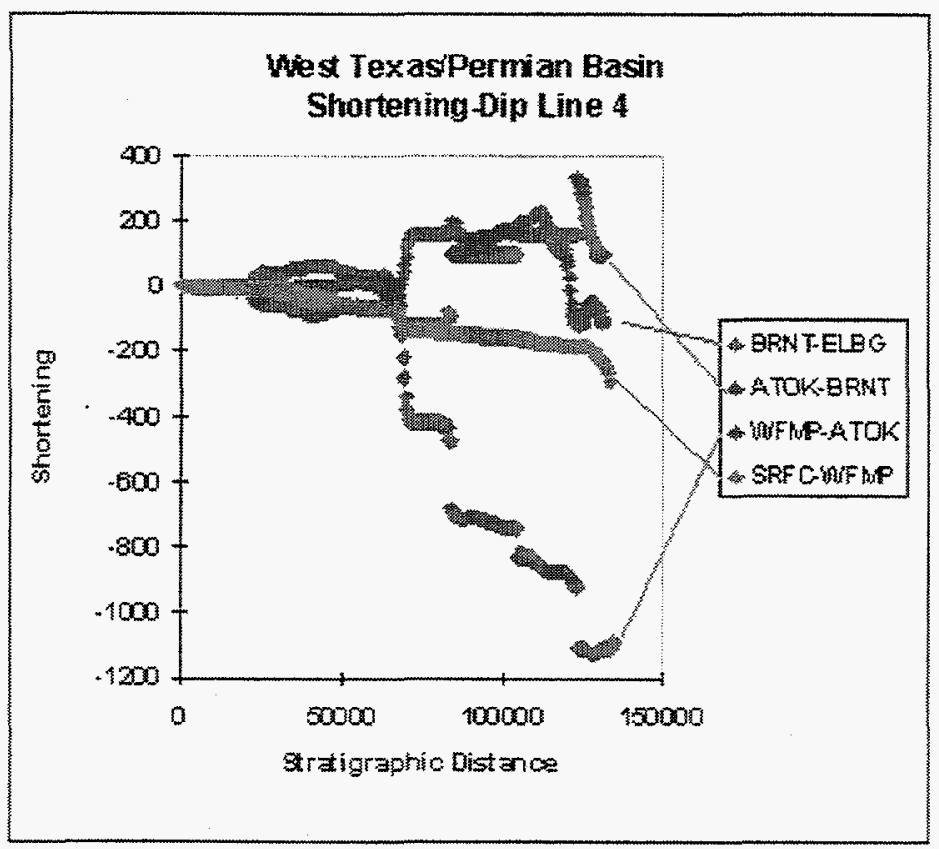

Figure 6E. Dip line just south of Figure $6 \mathrm{C}$. The Midland Basin in the $E$ is to the left, the Central Basin Platform and Delaware Basin are to the right. The shortening displayed here included the drape over the faults. The drape is cleary visible in the section, and the major faults are clearly located. The shortening predicted here is unreasonably large in comparison to that of Figure $6 \mathrm{C}$, which honored the faults. 


\section{Appendix A: Mapping Formation Tops from Commercial Data}

The formation mapped here and used in the reconstructions included the following tops:

\begin{tabular}{|c|c|c|}
\hline Ellenburger & $*$ & $\begin{array}{l}\text { These tops were selected to cover the general area as much as } \\
\text { possible, span the geologic ages important in the }\end{array}$ \\
\hline Simpson & & possible, span the geologic ages important in the \\
\hline Montoya & & development of the basin, and be definable using \\
\hline Fusselman & & commercially available data. Tops were recovered from the \\
\hline Woodford & & Petroleum Information Corporation data base, and these \\
\hline $\begin{array}{l}\text { Barnett } \\
\text { Atoka }\end{array}$ & * & \\
\hline $\begin{array}{l}\text { Atoka } \\
\text { Strawn } \\
\text { Canyon }\end{array}$ & & $\begin{array}{l}\text { Care was taken to edit probable bad data. The procedure for } \\
\text { carrying out these operations is described below. }\end{array}$ \\
\hline Wolfcamp & * & \\
\hline Clear Fork & & $\begin{array}{l}\text { Maps were made for all of the tops at the left; however, only } \\
\text { those tops flagged with an }\left({ }^{*}\right) \text { were used in the shortening }\end{array}$ \\
\hline Grayburg & & \\
\hline Yates & $*$ & \\
\hline Surface & $*$ & \\
\hline
\end{tabular}

Data were recovered from the Petroleum Information Corporation. Wells were screened for locations in Texas, presence of the tops above, and location with the geographic area of Figure 2.

Once recovered, the tops were gridded using the linear least squares algorithm in the Landmark Zycor mapping system. The grid node spacing was selected to be $500 \mathrm{~m}$, and the gridding was carried out with a search radius of $1 / 2$ the diagonal of the study area. The "sharp" statistical weight function was used.

At this point, the grids produced honored all the data given to the programs, regardless of quality. To detect errors in the control points, a macro procedure was applied to the grids. The errors appear most frequently as "bullseyes" on the maps. Reprductions of screen seen during the gridding are shown in Figures A-1 and A-2. The white contours show occasional unusual excursions from smooth trends and form tightly convoluted features we call bullseyes.

Our procedure is to regrid the same data at a lower resolution and with a "smooth" statistical weight function.. This reduced resolution will smooth out the high frequency "bullseyes", and if we reverse interpolate these surfaces at the well locations, the resulting values will differ too. The extent of the difference depends on the size of the error and the density of good control points around the bad ones. However, threshold misties of 10 to $50 \mathrm{ft}$ generally found most of the data base errors. Some poorly controlled locations had to be edited by hand. Recast as a process list, this procedure is: 
(1) Reverse interpolate the high resolution $1 / 2 \mathrm{~km}$ grids at the wells.

(2) Regrid the data with a reduced spatial resolution $(2 \mathrm{~km})$.

(3) Reverse interpolate the low resolution grids at the wells.

(4) Compare the reverse interpolated tops at the well locations.

(5) If the two interpolations at a well differ more than a threshold value, the top at that well is taken to be in error. It differs significantly from the trends its neighboring wells established.

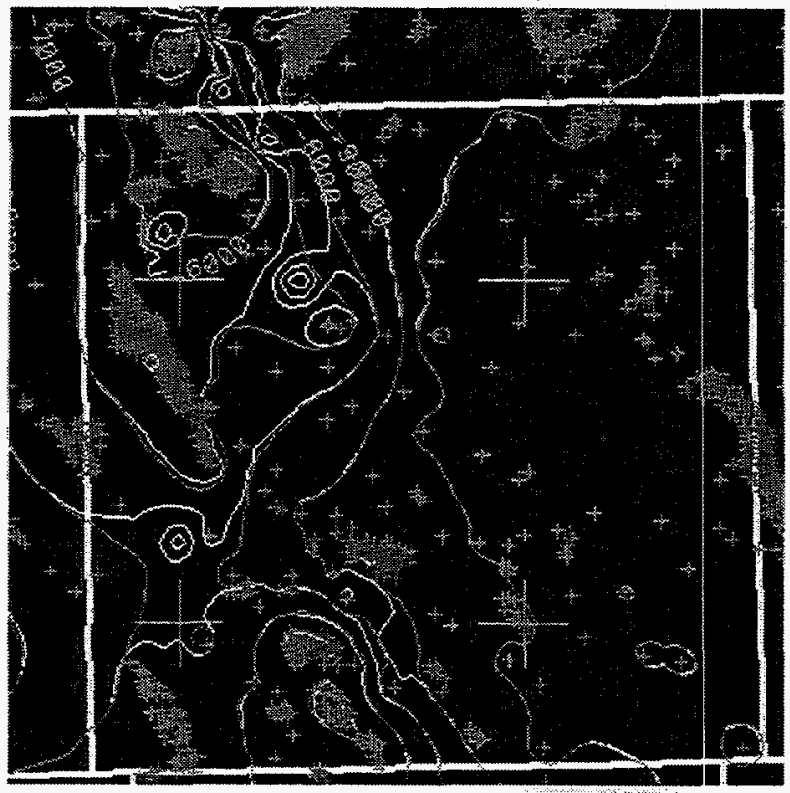

Figure A-1. Misties on a surface are exposed when they are gridded at two different resolutions. The $1 / 2 \mathrm{~km}$ resolution produced the white contours. The $2 \mathrm{~km}$ reolution produced the red contours. The high frequency, loopy features in the white contours indiucate misties in the control data. Our procedure was to reject these data points rather than try correct them. The data recovery for the formations chosen generally produced many suitable points for each surface.

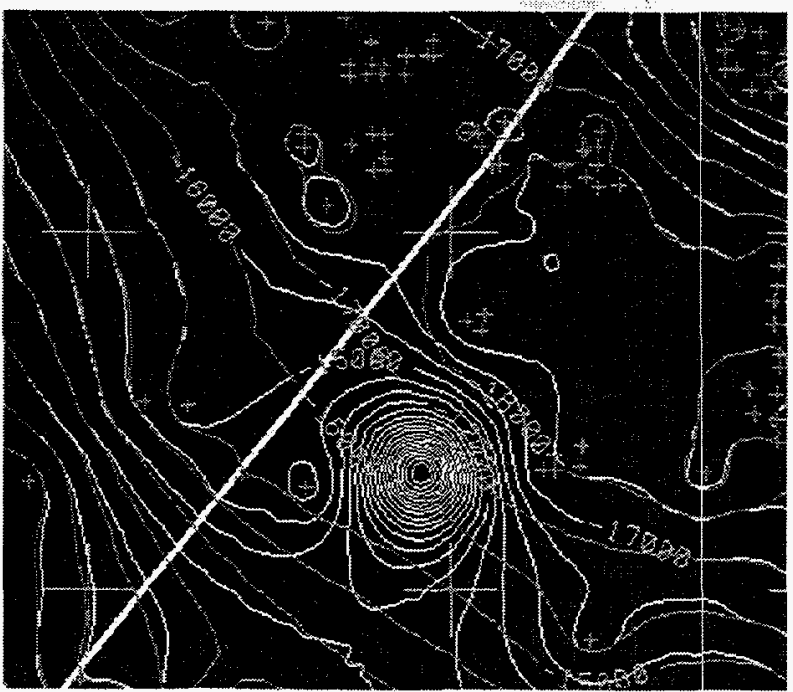

Figure A-2. Extreme mistie in the control data. The incorrect point has not only produced a severe bullseye, but it has distorted the surrounding contours as well. Nevertheless, the distortions do not extend much beyond four times the $1 / 2 \mathrm{~km}$ grid size in the high-resolution grid. Beyond that radius, the contours in the two grids are generally conformable.

A second source of grid problems stems from calculating the grids for the different tops. It is not formally possible to insure that no surface crossings occur. Our correction was to pick a few surfaces that were especially well controlled, like the Ellenburger, Wolfcamp, and trim the other surfaces to not cross them. For instance, the Simpson would be trimmed to not cross the Ellenburger, and the Montoya would be trimmed to 
not cross the Simpson or the Ellenburger. The surfaces like the Atoka, which are close to an upper bound like the Barnett, were trimmed from above and below.

All of the surfaces were resampled for use in the CIRFB simulator, and consistency was again established at that point. 


\section{Appendix B: Formation Tops}

Ellenburger

Barnett

Atoka

Wolfcamp

Yates

Surface

All maps are centered on Ector County Texas. They cover this county and the surrounding area. 


\section{Ellenburger}
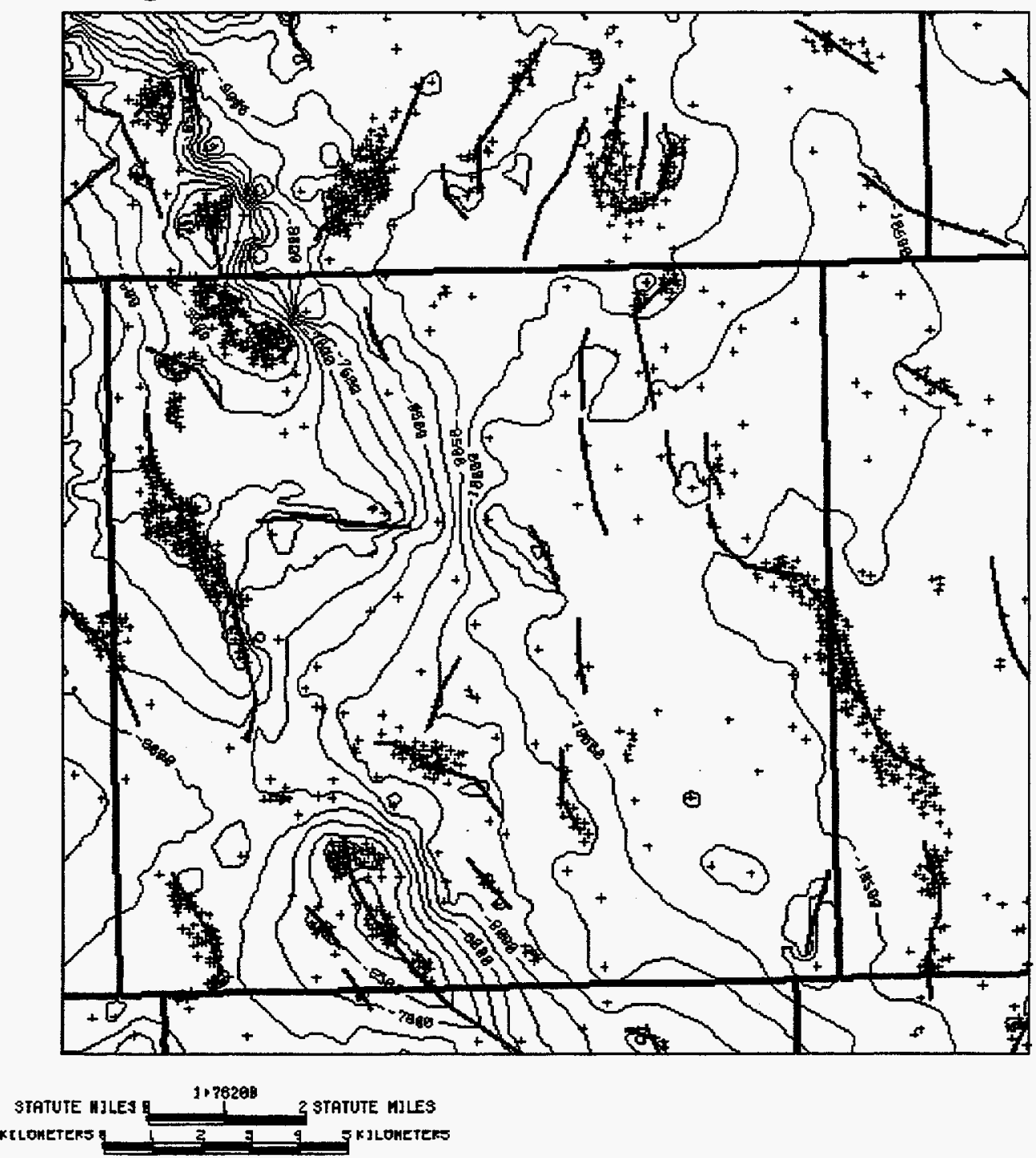

$\int_{10}^{1}$ 


\section{Barnett}

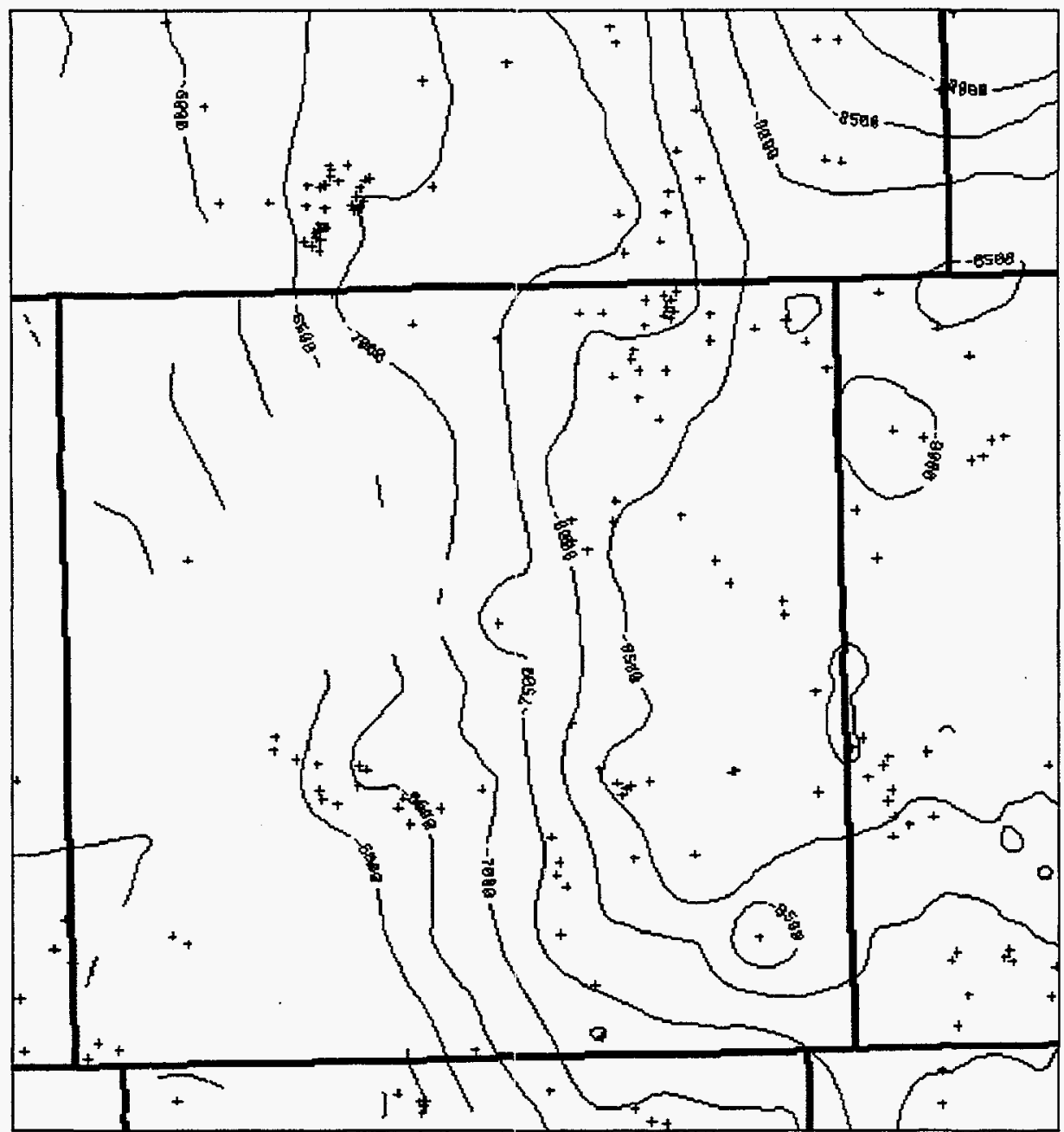

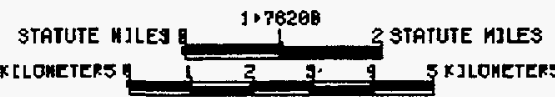

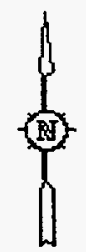




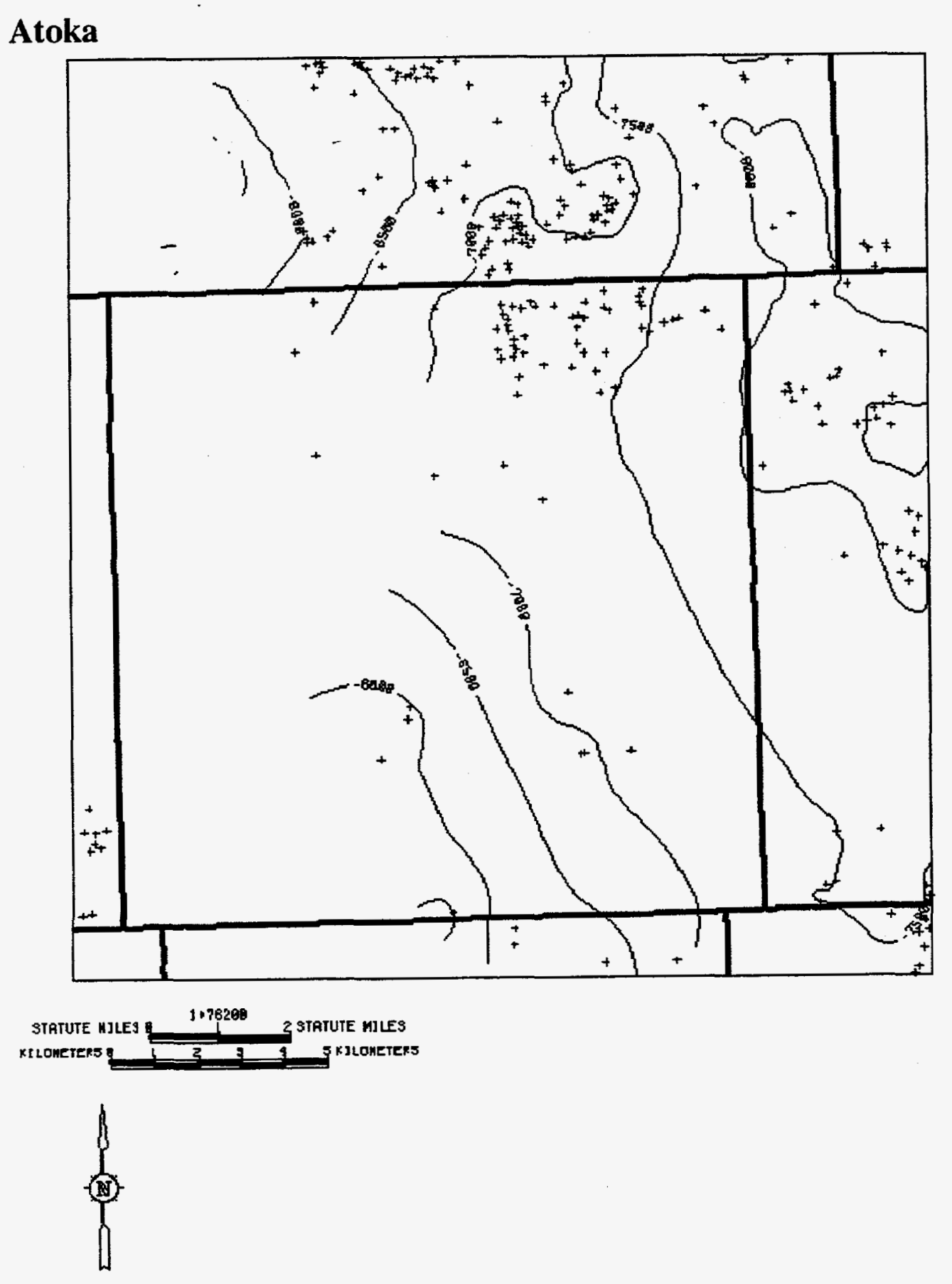




\section{Wolfcamp}

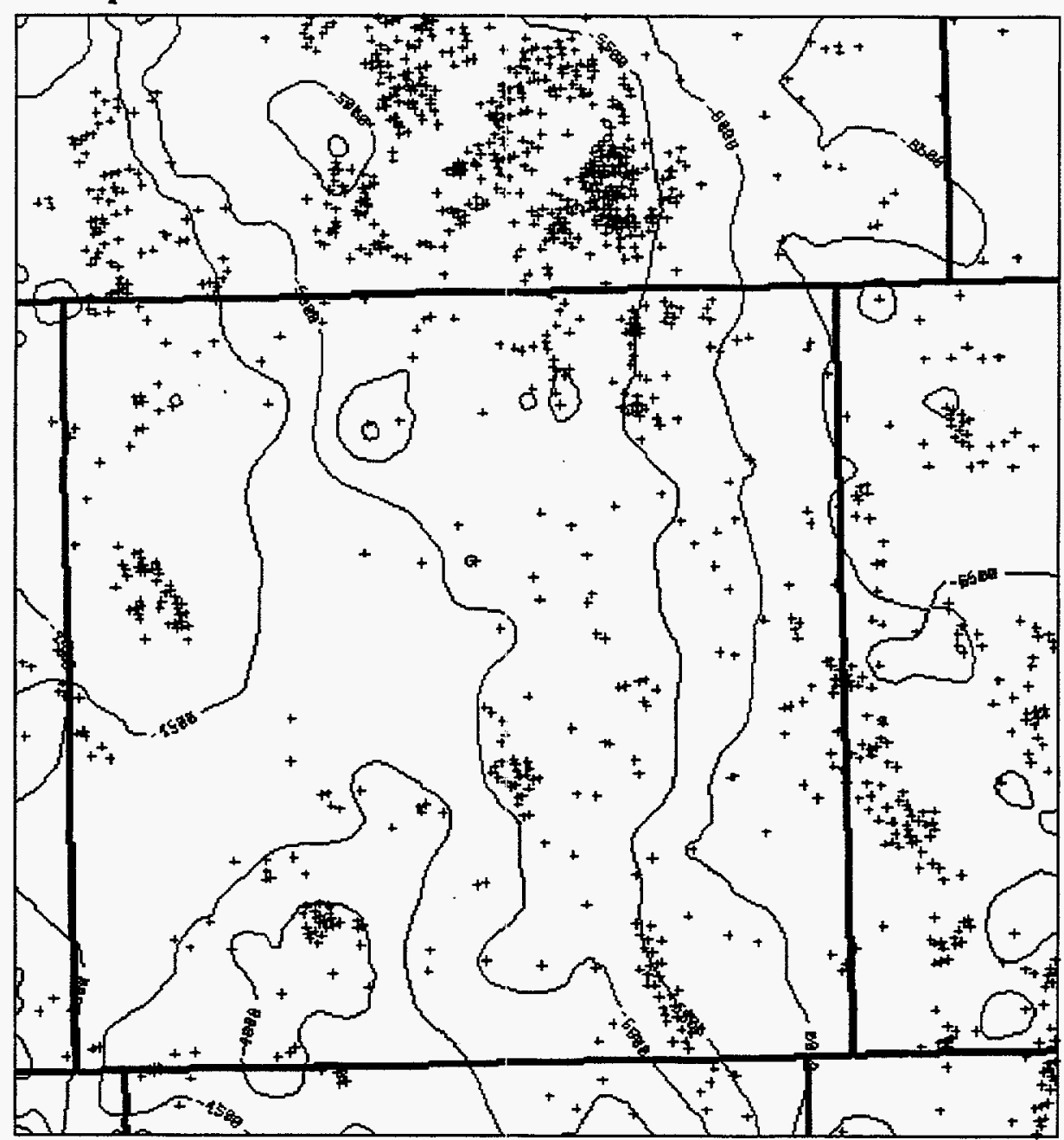

STATUTE HJLES :

1.76200 3 STATUTE U]LS

kLLONETERS

1 


\section{Yates}

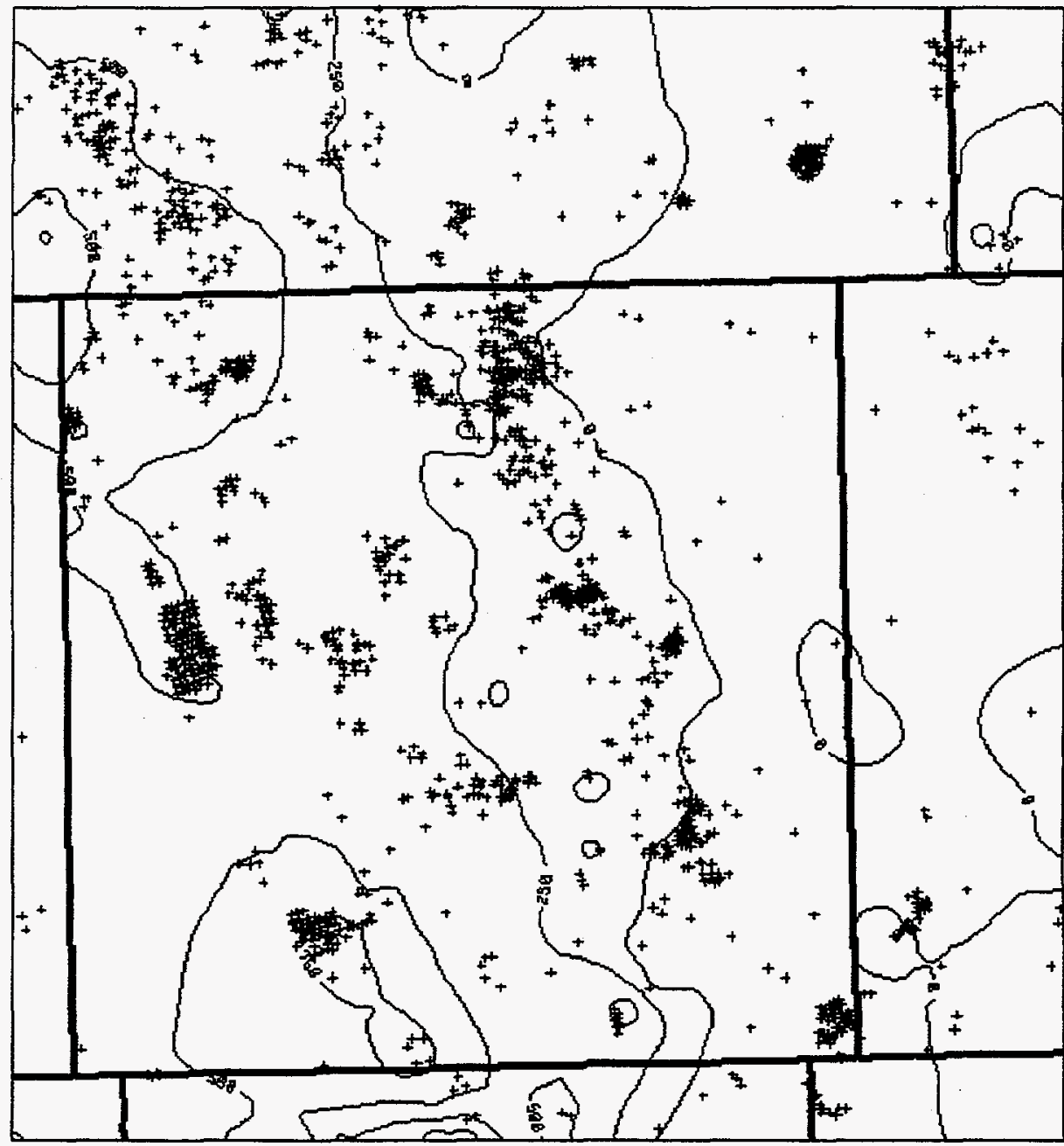

STOIUTE HIES 1.?6208

KtLDETERS

3 STRTUTE MILS

1 


\section{Surface}

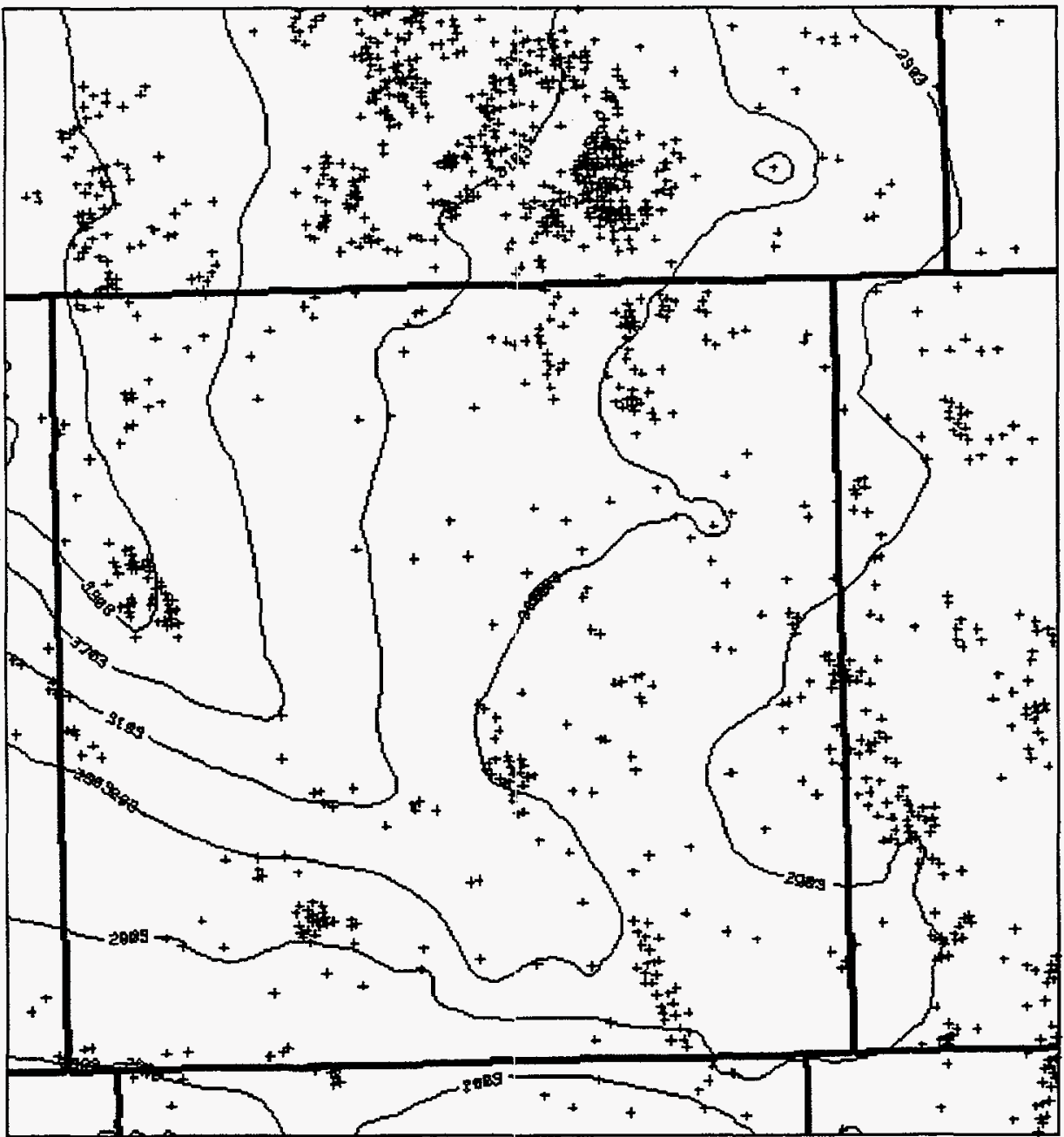

STATUTE HJLES I"P629B

KILONETERS : 3 i 3 KJLOMETERS

$\int_{1}^{1}$ 